\title{
Submicroscopic Structure of Cellulose from Nitrogen Sorption Measurements
}

\author{
By Charles M. Hunt, Raymond L. Blaine, and John W. Rowen
}

\begin{abstract}
When cotton linters were soaked in cold 10-percent sodium hydroxide, washed, and neutralized, and transferred successively to methyl alcohol and benzene, and carefully dried at reduced pressure, a surface area as high as 71.3 square meters per gram was obtained by the Brunauer, Emmett, Teller technique. Previous areas for untreated cotton were all below 1 square meter per gram. Linters carried through the above steps after soaking in water instead of alkali had an area as high as 47.3 square meters per gram. When the alkalitreated sample was conditioned in water vapor to 3.3 percent gain in weight, the surface decreased to 31.6 square meters per gram; further conditioning to an 11.0-percent gain in weight decreased the surface to 2.1 square meters per gram.

The isotherms of the treated samples showed strong hysteresis, whereas the isotherms of untreated cotton showed little or no hysteresis.

Calculations of pore size distribution by the method of Wheeler and Shull indicated these materials have rather narrow distributions, the alkali-treated material having a maximum at a pore radius of about 20 Angstroms and the water-soaked material a maximum at about 16 Angstroms.
\end{abstract}

\section{Introduction}

The view that native and regenerated cellulose fibers contain longitudinal submicroscopic channels, or that such a structure can be produced by imbibition of water has been suggested from a number of lines of evidence as, for example, X-ray and ultramicroscopic studies of fibers in which metals have been deposited from solution $[1,2,3] .^{2} \quad$ A review of this subject is presented by Frey-Wyssling [20] and Hock and Mark [4a]. The existence of channels in wet cellophane has been suggested to explain its use as a semipermeable membrane, and Valko [4b] has reviewed the measurement of pore diameters in this material by different methods and cites values, most of which lay between 40 and $60 \mathrm{~A}$. The observation of Collins $[5,6]$ that cotton and rayon fibers swell laterally but very little longitudinally upon imbibing water indicates that some sort of lateral separation of the chains occurs in the swelling process.

\footnotetext{
1 This paper will also appear in the January 1950 issue of the Textile

Research Journal.
2 Figures in brackets indicate the literature references at the end of this

2 Figures in brackets indicate the literature references at the end of this
Research Journal. paper.
}

Submicroscopic Structure of Cellulose

Previous work in this laboratory showed that the surface area of a cotton sample was 0.72 $\mathrm{m}^{2} / \mathrm{g}$ when based on the sorption of nitrogen at liquid nitrogen temperatures and calculated by the Brunauer, Emmett, Teller equation [16]. When this equation was applied to the data for the sorption of water at $25^{\circ} \mathrm{C}$ by the same cotton, a specific surface of $108 \mathrm{~m}^{2} / \mathrm{g}$ was obtained. From this it was evident that water had access to regions within the fiber unavailable to nitrogen. Shaw and coworkers made a similar kind of observation when they compared the water and nitrogen absorption of certain proteins [7] and sodium pectate [8]. However Assaf, Haas, and Purves $[9,10]$ reported that cotton linters soaked in sodium hydroxide and carried through a solvent exchange procedure had a calculated area as large as $64.7 \mathrm{~m}^{2} / \mathrm{g}$ available to nitrogen. Thus it appears that regions within the fiber ordinarily available only to water were made available to nitrogen.

The experiments reported here were undertaken to study the structure of expanded cellulose by low-temperature nitrogen sorption, because measurements of this type on other adsorbents have 
been found to have real significance. Cotton linters were carried through the procedure of Assaf, Haas, and Purves and nitrogen adsorptiondesorption isotherms were obtained. Pore size distributions were calculated from the desorption data as has been done for certain silica gels [11, 12] and other materials [13c]. The effect of adding water vapor to the expanded material was observed, and an experiment was carried out to see if high nitrogen sorption could be obtained with cotton linters presoaked with water instead of alkali.

\section{Experimental Part}

The sample of cotton linters used in this work was furnished by the Hercules Powder Co. through the courtesy of H. M. Spurlin and Peter Van Wyck. It was designated as 05843 Grade $27 \mathrm{LV}$ Cotton Seed Hull Shavings Pulp. According to descriptive material furnished by the company, chemical cotton of this type is digested with dilute alkali and bleached. The sample had a reported ${ }^{3}$ viscosity of $608 \mathrm{sec}$ in $2.5 \mathrm{~g} / 100 \mathrm{ml}$ concentration in ACS cuprammonium solvent, corresponding to an intrinsic viscosity of about 9 and a degree of polymerization of about 1,800 . The material was used without further purification. The methyl alcohol and benzene used in the solvent exchange described in this study were dried by distillation from sodium.

The control sample of cotton linters (sample $A$ ) received no treatment. Sample $B$ was put through the procedure described by Assaf, Haas, and Purves [9], neutralizing the sample after removing most of the alkali. No preliminary dewaxing was performed, as the material wet readily with water. After drying in vacuum, the sample was stored several weeks over a drying agent and paraffin before use. The paraffin was used as an absorbent for desorbed benzene vapor. Sample $C$ was prepared by soaking $5 \mathrm{~g}$ of cotton linters for $3 \mathrm{hr}$ in water at room temperature. The sample was then pressed to remove excess water and transferred to $1 / 3$ l of absolute methyl alcohol. After $30 \mathrm{~min}$ the sample was pressed and transferred to a second portion of methanol. The process was repeated once more with methyl alcohol and twice with benzene. The sample was vacuum dried by intermittent evacuation to a pressure of about $25 \mathrm{~mm}$ $\mathrm{Hg}$ and stored over a drying agent and paraffin.

${ }^{3}$ Private communication from Peter Van Wyck.
This procedure is similar to that of Assaf, Haas, and Purves, but the preliminary swelling was done with water alone at room temperature instead of 10-percent sodium hydroxide in an ice bath.

Five to seven $\mathrm{g}$ of samples $A, B$, and $C$ were quickly transferred from the desiccator and sealed into glass holders. A glass plug was placed on top of each sample and this permitted the sealing flame to be applied 2 to $3 \mathrm{in}$. from the cotton without unduly increasing dead space. The tips of the holders were drawn out so that they could be easily broken off and resealed. Samples $A$ and $C$ were outgassed overnight at room temperature, or longer if necessary, to obtain a vacuum of $10^{-6} \mathrm{~mm}$ $\mathrm{Hg}$, and nitrogen adsorption-desorption isotherms were obtained. Nitrogen adsorption-desorption measurements were made on sample $B$, both after outgassing at liquid nitrogen temperature (determinations 1, 2, and 3), and after outgassing at room temperature (determination 4), in order to see if large differences were obtained. Sample $B$ was then conditioned at 20- to 25-percent relative humidity. Conditioning was accomplished by passing nitrogen through sulfuric acid of proper concentration, glass wool, and finally through the sample. Passage through the sample was achieved by breaking the tip of the holder, and after constant weight was attained the tip was resealed. The sample was outgassed under liquid nitrogen to retain the water that had been added, and nitrogen adsorption-desorption measurements were made (determinations 5 and 6 ). The process was repeated after conditioning the sample at 70 - to 75-percent relative humidity (determinations 7 and 8). The sample was then dried by passing nitrogen, dried with magnesium perchlorate, through the sample. Nitrogen adsorption-desorption measurements were made after outgassing at room temperature. This provided a means of seeing if any of the nitrogen sorptive capacity of the sample lost by hydration could be regained by removal of the water (determinations 9 and 10).

Nitrogen adsorption measurements were made with an apparatus similar to that described by Emmett [14]. The saturation vapor pressure of the nitrogen at the temperature of the liquid nitrogen bath was determined by a vapor pressure thermometer, using the purified nitrogen employed for the adsorption experiment. A correction for the nonideality of nitrogen was calculated, assuming the volume of nitrogen in the dead space at 
$760 \mathrm{~mm} \mathrm{Hg}$ pressure was 5 percent greater than that calculated from the ideal gas laws, and that the percentage deviation varied linearly with pressure, being negligible at very low partial pressures.

Pressure-volume measurements covering a range of $p / p_{0}$ from less than 0.1 to above 0.9 were made, where $p$ is the pressure of nitrogen above the sample and $p_{0}$ is the vapor pressure of liquid nitrogen at the same temperature. Each adsorption-desorption isotherm required 2 or 3 days to complete. Apparently longer times were required to reach equilibrium on the steeper portions of the curves than the flatter portions. Final readings were recorded when two pressure readings taken 10 min apart did not differ by more than $0.1 \mathrm{~mm}$ $\mathrm{Hg}$. Pressure readings obtained in this way usually agreed within 1 or 2 percent with readings obtained when the sample was left overnight, the drift being in the direction of slightly greater nitrogen adsorption in adsorption measurements and slightly less nitrogen adsorption in desorption measurements.

\section{Nitrogen Sorption Isotherms}

The volumes of nitrogen adsorbed per gram of sample are given in table 1 , and typical isotherms are shown in figures 1 and 2. The untreated cotton linters (fig. 2 curve $A$ ) adsorbed much less nitrogen than the other samples and had a type II isotherm [13a]. That is, the curve gave no indication of leveling off up to the highest partial pressure measured. No hysteresis was observed within the limits of experimental error. The adsorption of nitrogen by untreated cotton is conceived as a multilayer adsorption process in which capillary condensation plays little or no part.

The cotton swollen with alkali and subjected to solvent exchange (fig. 1 curve $B$ ) and the cotton swollen with water and given solvent exchange (fig. 2 curve $C$ ) had what appeared to be type IV isotherms [13a]. Strong hysteresis was observed with inflection points in the desorption curves at partial pressures of 0.49 and 0.47 , respectively.

When sample $B$ was conditioned to a 3.3 percent gain in weight at a relative humidity of 20 to 25 percent, the isotherm (fig. 1 curve $B^{\prime}$ ) also appeared to be type IV with strong hysteresis. The sorptive capacity was smaller, however.
When sample $B$ was further conditioned at 70 to 75 percent relative humidity to a weight 11.0 percent greater than the weight of the original sample, the form of the isotherm changed completely (fig. 1 curve $B^{\prime \prime}$ ). It was more like a type II curve, up

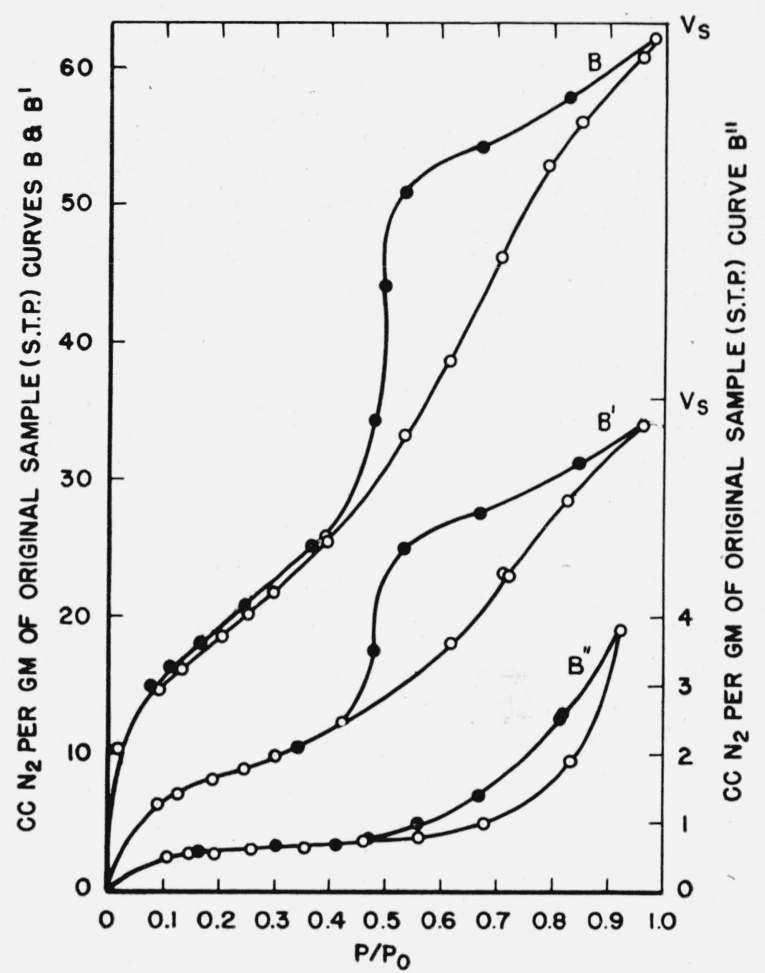

Figure 1. Nitrogen adsorption-desorption isotherms.

B, Alkali swelled, solvent exchanged cotton linters (determination 4); $\mathrm{B}^{\prime}$, B conditioned at 20- to 25-percent relative humidity (determination 5); $\mathrm{B}^{\prime \prime}, \mathrm{B}^{\prime}$ conditioned at 70- to 75 -percent relative humidity (determination 8).

-, desorption; $\bigcirc$, adsorption.

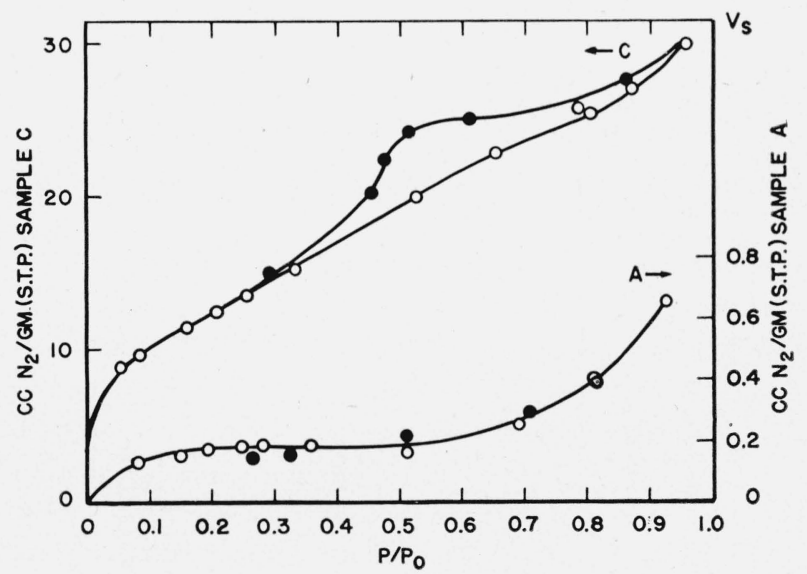

Figure 2. Nitrogen adsorption-desorption isotherms.

A, Control cotton linters (determination 1); C, water swelled, solvent exchanged cotton linters (determination 2). @, Desorption; $\bigcirc$, adsorption. 
TABLE 1. Nitrogen sorbed by cotton linters

\begin{tabular}{|c|c|c|c|c|c|c|c|c|c|c|c|c|c|c|c|c|c|c|c|c|c|c|c|c|c|c|c|}
\hline \multicolumn{4}{|c|}{ Sample A-control } & \multicolumn{20}{|c|}{ Sample B } & \multicolumn{4}{|c|}{ Sample C } \\
\hline \multicolumn{2}{|c|}{$\begin{array}{l}\text { Determina- } \\
\text { tion } 1^{\mathrm{a}}\end{array}$} & \multicolumn{2}{|c|}{$\begin{array}{l}\text { Determina- } \\
\text { tion } 2\end{array}$} & \multicolumn{2}{|c|}{$\begin{array}{l}\text { Determina- } \\
\quad \text { tion } 1\end{array}$} & \multicolumn{2}{|c|}{$\begin{array}{l}\text { Determina- } \\
\text { tion } 2\end{array}$} & \multicolumn{2}{|c|}{$\begin{array}{l}\text { Determina- } \\
\text { tion } 3\end{array}$} & \multicolumn{2}{|c|}{$\begin{array}{l}\text { Determina- } \\
\text { tion } 4^{\mathrm{b}}\end{array}$} & \multicolumn{2}{|c|}{$\begin{array}{l}\text { Determina- } \\
\text { tion } 5^{\circ}\end{array}$} & \multicolumn{2}{|c|}{$\begin{array}{l}\text { Determina- } \\
\text { tion } 6\end{array}$} & \multicolumn{2}{|c|}{$\begin{array}{l}\text { Determina- } \\
\text { tion } 7\end{array}$} & \multicolumn{2}{|c|}{$\begin{array}{l}\text { Determina- } \\
\text { tion } 8 \mathrm{~d}\end{array}$} & \multicolumn{2}{|c|}{$\begin{array}{l}\text { Determina- } \\
\quad \text { tion } 9\end{array}$} & \multicolumn{2}{|c|}{$\begin{array}{l}\text { Determina- } \\
\quad \text { tion } 10\end{array}$} & \multicolumn{2}{|c|}{$\begin{array}{l}\text { Determina- } \\
\text { tion } 1\end{array}$} & \multicolumn{2}{|c|}{$\begin{array}{l}\text { Determina- } \\
\text { tion } 2{ }^{\circ}\end{array}$} \\
\hline$p / p_{0}$ & $\begin{array}{c}\mathrm{ml} \mathrm{N}_{2} \\
\text { per } \\
\text { gram }\end{array}$ & $\mathrm{p} / p_{0}$ & $\mid \begin{array}{c}\mathrm{ml} \mathrm{N}_{2} \\
\text { per } \\
\text { gram }\end{array}$ & $p / p_{0}$ & $\begin{array}{c}\mathrm{ml} \mathrm{N}_{2} \\
\text { per } \\
\text { gram }\end{array}$ & $\mathrm{p} / p_{0}$ & $\mid \begin{array}{c}\mathrm{ml} \mathrm{N}_{2} \\
\text { per } \\
\text { gram }\end{array}$ & $p / p_{0}$ & $\begin{array}{c}\mathrm{ml} \mathrm{N}_{2} \\
\text { per } \\
\text { gram }\end{array}$ & $p / p_{0}$ & $\mid \begin{array}{c}\mathrm{ml} \mathrm{N}_{2} \\
\text { per } \\
\text { gram }\end{array}$ & $p / p_{0}$ & $\mid \begin{array}{c}\mathrm{ml} \mathrm{N}_{2} \\
\text { per } \\
\text { gram }\end{array}$ & $p / p_{0}$ & 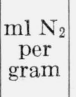 & $p / p_{0}$ & $\begin{array}{c}\mathrm{ml} \mathrm{N}_{2} \\
\text { per } \\
\text { gram }\end{array}$ & $p / p_{0}$ & $\mid \begin{array}{c}\mathrm{ml} \mathrm{N}_{2} \\
\text { per } \\
\text { gram }\end{array}$ & $p / p_{0}$ & $\mid \begin{array}{c}\mathrm{ml} \mathrm{N}_{2} \\
\text { per } \\
\text { gram }\end{array}$ & $p / p_{0}$ & $\begin{array}{c}\mathrm{ml} \mathrm{N}_{2} \\
\text { per } \\
\text { gram }\end{array}$ & $p / p_{0}$ & $\begin{array}{c}\mathrm{ml} \mathrm{N}_{2} \\
\text { per } \\
\text { gram }\end{array}$ & $p / p_{\theta}$ & $\begin{array}{c}\mathrm{ml} \mathrm{N}_{2} \\
\text { per } \\
\text { gram }\end{array}$ \\
\hline \multicolumn{2}{|c|}{ Adsorption } & \multicolumn{2}{|c|}{ Adsorption } & Adsorp & ption & Adsor & ption & Adsorn & ption & Adsorl & ption & Adsor & ption & Adsor] & ption & Adsorp & ption & Adsor & ption & Adsor & ption & Adsor & ption & Adsorl & ption & Adsor & ption \\
\hline 0.081 & 0.14 & 0.075 & 0.11 & 0.006 & 7.0 & 0.090 & 14. 2 & 0.024 & 10.5 & 0.018 & 10.3 & 0.079 & 6.4 & 0.096 & 6.7 & 0.113 & 0.52 & 0.107 & 0.48 & 0.114 & 0.51 & 0.128 & 0.52 & 0.027 & 7.8 & 0.055 & 8.8 \\
\hline .152 & .15 & .138 & .13 & .029 & 11.6 & .131 & 15.7 & .031 & 11.1 & .090 & 14.7 & .126 & 7.1 & .125 & 7.1 & .154 & .56 & .146 & .53 & .156 & .54 & .155 & .55 & .037 & 7.7 & .084 & 9.7 \\
\hline .194 & .17 & .185 & .13 & .038 & 12.3 & .251 & 19.5 & .120 & 15.1 & .131 & 16. 2 & .190 & 8.1 & .155 & 7.5 & .202 & .60 & .191 & .54 & .204 & .56 & .182 & .55 & .120 & 10.3 & .159 & 11.5 \\
\hline .249 & .19 & .228 & .13 & .076 & 14.2 & .287 & 20.8 & .149 & 16.1 & .203 & 18.6 & .245 & 8.9 & .213 & 8.4 & .257 & .63 & .261 & .62 & .267 & .61 & .227 & .60 & .192 & 12.0 & .207 & 12.5 \\
\hline .283 & .19 & .280 & .14 & .109 & 15.5 & .362 & 23.6 & .177 & 16.9 & .250 & 20.2 & .302 & 9.8 & .261 & 9.1 & .312 & .65 & .355 & .64 & .363 & .64 & .250 & .61 & .269 & 13.8 & .256 & 13.6 \\
\hline .360 & .19 & .346 & .11 & .144 & 17.3 & .436 & 26.8 & .239 & 18.9 & .294 & 21.8 & .419 & 12.0 & & & & & .463 & .72 & .471 & .72 & & & .316 & 14. 9 & .333 & 15.4 \\
\hline .516 & .17 & .430 & .19 & .178 & 17.9 & .519 & 31.0 & .274 & 20.2 & .389 & 25.6 & .616 & 18.1 & & & & & .562 & .79 & .596 & .84 & & & & & .525 & 20.0 \\
\hline .692 & .25 & .568 & .17 & .209 & 19.0 & .589 & 35.6 & .347 & 22.8 & .387 & 25.9 & .718 & 23.0 & & & & & .678 & .97 & .747 & 1. 23 & & & & & .654 & 22.8 \\
\hline .813 & .41 & .672 & .19 & .240 & 20.0 & .641 & 39.2 & .422 & 25.9 & .531 & 33.3 & .716 & 23.1 & & & & & .832 & 1.90 & .855 & 2. 16 & & & & & .806 & 25.4 \\
\hline .928 & .66 & .789 & .22 & .274 & 21.3 & .702 & 45.5 & .506 & 30.2 & .611 & 38.8 & .826 & 28.5 & & & & & .923 & 3. 83 & .942 & 4. 31 & & & & & .786 & 25.8 \\
\hline Desor & ption & .931 & .47 & .320 & 23.0 & $\begin{array}{l}.827 \\
.878\end{array}$ & $\begin{array}{l}53.6 \\
55.9\end{array}$ & $\begin{array}{l}.573 \\
.636\end{array}$ & $\begin{array}{l}34.5 \\
39.5\end{array}$ & $\begin{array}{l}.701 \\
.783\end{array}$ & \begin{tabular}{|l|}
46.4 \\
53.0
\end{tabular} & .959 & 34.0 & & & & & Desor & ption & Desor & ption & & & & & $\begin{array}{l}.812 \\
.958\end{array}$ & $\begin{array}{l}27.1 \\
30.0\end{array}$ \\
\hline & & Desor & ption & & & .987 & 61.1 & .632 & 39.8 & .844 & 56.2 & Desor & ption & & & & & & & & & & & & & Desor & ption \\
\hline $\begin{array}{r}0.813 \\
.709\end{array}$ & $\begin{array}{r}0.38 \\
.30\end{array}$ & & 0. 20 & & & Desor & ption & $\begin{array}{l}.715 \\
.819\end{array}$ & $\begin{array}{l}46.6 \\
54.0\end{array}$ & $\begin{array}{r}.954 \\
974\end{array}$ & $\begin{array}{l}61.0 \\
62.3\end{array}$ & 0.842 & 31.2 & & & & & $\begin{array}{r}0.819 \\
.813\end{array}$ & $\begin{array}{l}2.59 \\
2.54\end{array}$ & $\begin{array}{r}.840 \\
.847\end{array}$ & $\begin{array}{l}2.90 \\
2.92\end{array}$ & & & & & & \\
\hline .515 & .21 & .607 & .18 & & & & & .833 & 54. 5 & & & .665 & 27.6 & & & & & .667 & 1. 38 & .715 & 1.68 & & & & & 0.862 & 27.6 \\
\hline .327 & .18 & .468 & .14 & & & 0.804 & 56.0 & .942 & 59.3 & Desor & ption & .531 & 25.0 & & & & & .555 & 0.96 & .598 & 1.05 & & & & & .613 & 25.1 \\
\hline & .17 & .381 & .18 & & & .686 & 53.4 & .976 & 61.3 & & & .478 & 17.6 & & & & & .469 & $\begin{array}{l}.74 \\
68\end{array}$ & & & & & & & $\begin{array}{r}.515 \\
475\end{array}$ & $\begin{array}{l}24.3 \\
22.4\end{array}$ \\
\hline & & $\begin{array}{l}.271 \\
.239\end{array}$ & $\begin{array}{l}.18 \\
.18 \\
.20\end{array}$ & & & $\begin{array}{r}.004 \\
.495 \\
442\end{array}$ & 42.9 & Desor & ption & $\begin{array}{r}0.825 \\
.665\end{array}$ & $\begin{array}{l}58.0 \\
54.3\end{array}$ & .540 & & & & & & .304 & .65 & & & & & & & $\begin{array}{l}.455 \\
.291\end{array}$ & $\begin{array}{l}20.3 \\
15.1\end{array}$ \\
\hline & & .195 & .16 & & & $\begin{array}{l}.442 \\
.308\end{array}$ & $\begin{array}{l}28.0 \\
22.1\end{array}$ & 0.812 & 56.7 & $\begin{array}{l}.527 \\
.494\end{array}$ & $\begin{array}{l}51.0 \\
44.2\end{array}$ & & & & & & & & & & & & & & & & \\
\hline & & & & & & .277 & 21.0 & .789 & 56.1 & .493 & 44.0 & & & & & & & & & & & & & & & & \\
\hline & & & & & & $\begin{array}{l}.206 \\
.156\end{array}$ & $\begin{array}{l}18.6 \\
17.0\end{array}$ & $\begin{array}{l}.656 \\
.522\end{array}$ & $\begin{array}{l}53.1 \\
49.9\end{array}$ & $\begin{array}{r}.475 \\
363\end{array}$ & \begin{tabular}{|l|}
34.3 \\
25.2
\end{tabular} & & & & & & & & & & & & & & & & \\
\hline & & & & & & .136 & 16.4 & $\begin{array}{l}.022 \\
.508\end{array}$ & $\begin{array}{l}49.9 \\
49.5\end{array}$ & .245 & 20.9 & & & & & & & & & & & & & & & & \\
\hline & & & & & & & & .491 & 46.5 & .163 & 18.1 & & & & & & & & & & & & & & & & \\
\hline & & & & & & & & .496 & 46.1 & .109 & 16.3 & & & & & & & & & & & & & & & & \\
\hline & & & & & & & & $\begin{array}{l}.475 \\
.434\end{array}$ & $\begin{array}{l}33.3 \\
28.1\end{array}$ & .074 & 15.0 & & & & & & & & & & & & & & & & \\
\hline & & & & & & & & .360 & 24.6 & & & & & & & & & & & & & & & & & & \\
\hline & & & & & & & & .243 & $\begin{array}{l}20.4 \\
17.7\end{array}$ & & & & & & & & & & & & & & & & & & \\
\hline & & & & & & & & $\begin{array}{l}.161 \\
.107\end{array}$ & $\begin{array}{l}17.7 \\
16.0\end{array}$ & & & & & & & & & & & & & & & & & & \\
\hline & & & & & & & & .072 & 14.7 & & & & & & & & & & & & & & & & & & \\
\hline & & & & & & & & .050 & 13.7 & & & & & & & & & & & & & & & & & & \\
\hline
\end{tabular}

요 a Plotted in figure 2 as curve A.

b Plotted in figure 1 as curve $\mathrm{B}$.

\$ $D$ Plotted in figure 1 as curve $\mathrm{B}^{\prime}$.

e Plotted in figure 2 as curve C. 
to the highest partial pressure measured, and showed measurable hysteresis with both branches convex to the pressure axis.

When sample $B$ was redried after conditioning at 70 to 75 percent relative humidity an isotherm identical with curve $B^{\prime \prime}$ in figure 1 was obtained.

\section{Surface Areas}

The volume of nitrogen required to cover the adsorbate with a unimolecular layer was determined from nitrogen adsorption data between $p / p_{0}$ values of 0.05 and 0.3 by methods already described $[13 b, 14,15]$. Surface areas were calculated from this volume assuming each nitrogen molecule to cover an area of $16.2 \mathrm{~A}^{2}$. The values are summarized in table 2. Each value in the table represents a single determination, and they are listed in the order in which they were made.

TABLE 2. Summary of surface area determinations

\begin{tabular}{|c|c|c|}
\hline & $\begin{array}{l}\text { Determi- } \\
\text { nation } \\
\text { No. }\end{array}$ & $\begin{array}{c}\text { Specific } \\
\text { surface, } \\
\text { square } \\
\text { meters per } \\
\text { gram of } \\
\text { sample }\end{array}$ \\
\hline $\begin{array}{l}\text { Sample A, control, outgassed at room tem- } \\
\text { perature. }\end{array}$ & $\left\{\begin{array}{l}1 \\
2\end{array}\right.$ & $\begin{array}{r}0.6 \\
.5\end{array}$ \\
\hline $\begin{array}{l}\text { Sample } \mathrm{B}, \mathrm{NaOH} \text { and solvent exchange, and } \\
\text { outgassed at liquid nitrogen temperature... }\end{array}$ & $\begin{array}{l}1 \\
2 \\
3\end{array}$ & $\begin{array}{l}71.3 \\
68.2 \\
67.7\end{array}$ \\
\hline Outgassed at room temperature & 4 & 70.4 \\
\hline $\begin{array}{l}\text { Sample B, conditioned at } 20 \text { to } 25 \% \mathrm{RH} \text {, and } \\
\text { outgassed at liquid nitrogen temperature }\end{array}$ & $\begin{array}{l}5 \\
6\end{array}$ & $\begin{array}{l}31.6 \\
30.8\end{array}$ \\
\hline $\begin{array}{l}\text { Sample B, conditioned at } 70 \text { to } 75 \% \mathrm{RH} \text {, and } \\
\text { outgassed at liquid nitrogen temperature }\end{array}$ & $\begin{array}{l}7 \\
8\end{array}$ & $\begin{array}{r}2.1 \\
2.0\end{array}$ \\
\hline $\begin{array}{l}\text { Sample B, redried and outgassed at room } \\
\text { temperature }\end{array}$ & $\begin{array}{r}9 \\
10\end{array}$ & $\begin{array}{l}2.0 \\
2.1\end{array}$ \\
\hline $\begin{array}{l}\text { Sample C, solvent exchange only, and out- } \\
\text { gassed at room temperature }\end{array}$ & $\begin{array}{l}1 \\
2\end{array}$ & $\begin{array}{l}47.3 \\
46.5\end{array}$ \\
\hline
\end{tabular}

The area of 0.5 to $0.6 \mathrm{~m}^{2} / \mathrm{g}$ for untreated cotton linters is comparable with $0.72 \mathrm{~m}^{2} / \mathrm{g}$ previously obtained in this laboratory for a cotton yarn [16]. This is slightly larger than the value of $0.16 \mathrm{~m}^{2} / \mathrm{g}$ reported by Howell and Jackson [17] from microscopic measurements. This suggests that there may be a few accessible surface irregularities and pores, but nitrogen does not penetrate the untreated cotton fiber to any great extent.

However, when the linters were given the treatment of Assaf, Haas, and Purves a large surface was obtained, such as they reported. Successive additions of water to the sample greatly decreased the surface available to nitro- gen, and when the water was removed the surface remained at the same low value. The sensitivity of surface area to small amounts of water indicates that refinements aimed at the complete removal and rigorous exclusion of water would lead to higher surface areas than those given in table 1 .

The collapse of expanded cellulose upon wetting and drying suggests that the expanded material is in an unstable state. Recent unpublished work of $\mathrm{P}$. H. Hermans ${ }^{4}$ indicates that the expanded cellulose has an X-ray diffraction pattern that is somewhat different from that of native cellulose (cellulose I). Since expanded cellulose tends to revert to cellulose I upon wetting, it appears that the water molecules assist the cellulose in the expanded state in getting over a special energy barrier. Water probably facilitates lateral and transverse ordering through the formation of hydrogen bonds. It is believed that this ability of the cellulose molecule to become linked with other cellulose molecules by means of intermolecular hydrogen bonding is responsible for many of the physical properties of cellulose, such as insolubility and strength.

Swelling with water followed by solvent exchange from methyl alcohol to benzene without prior alkali treatment also produced a large increase in the calculated surface area of the cotton linters. Thus, although 10 percent sodium hydroxide undoubtedly produced structural changes in the cotton fiber, the use of alkali was not necessary to make comparatively large regions within the fiber available to nitrogen. A paper by Kistler is of interest in this connection [18]. He prepared aerogels from a large number of inorganic and organic materials by substituting a swelling liquid within the gel by a liquid that could be evaporated above its critical temperature in an autoclave. Thus, it was possible to replace the liquid in the structure by a gas without allowing the surface of the liquid to "recede within the gel." Kistler states that this last condition is quite important. He prepared an aerogel from cellophane by extracting the wet material with ether, followed by propane. The propane was removed in an autoclave at $115^{\circ} \mathrm{C}$.

The procedure employed here differed in at least one important respect from that of Kistler in that the final liquid was benzene, which was removed at room temperature. However the

\footnotetext{
${ }^{4}$ Communication through H. Mark to one of the authors.
} 
high sorptive capacity for nitrogen suggests the material had some of the properties of an aerogel. Apparently cotton linters possessed sufficient rigidity to retain much of the expanded structure even though the benzene-air interface was allowed to "recede within the gel". As already noted [10] water cannot be removed in this way without collapsing the expanded structure of cellulose.

It is to be noted in table 2 that a repeated surface area measurement on the expanded material is usually slightly lower than the preceding measurement. This again suggests that the expanded state is unstable.

\section{Pore Size Distribution}

Hysteresis in the sorption isotherms of samples $B$ and $C$ has suggested that capillary condensation plays a part in the process. Although it is possible to interpret hysteresis other than by capillary condensation, and modern statistical mechanical treatments of sorption do not explicitly interpret it in terms of capillary condensation [19], hysteresis in the isotherms of rigid solids has generally been attributed to this mechanism. Brunauer [13c] has reviewed much of the work on this subject. The postulation of channels in wet cellulose from lines of evidence previously mentioned suggested that pores might exist in cellulose from which water had been removed by solvent exchange.

Pore size distributions have been calculated by the method of Wheeler [21] and Shull [11] from the desorption isotherms plotted in figure 1 , curves $\mathrm{B}$ and $\mathrm{B}^{\prime}$, and figure 2 , curve $\mathrm{C}$. These distributions have been plotted in figure 3 .

The method is briefly outlined here. It corrects the capillary radii, as calculated by the Kelvin equation, for the thickness of the layer of gas laid down by multilayer adsorption. The pore size distribution is based upon integration of the equation:

where:

$$
V_{s}-V=\pi \int_{R}^{\infty}(r-t)^{2} L(r) d r
$$

$V_{s}$ is the volume of gas adsorbed at saturation pressure;

$V$ is the volume of gas adsorbed at any given partial pressure;

$r$ is the pore radius;

$t$ is the thickness of gas laid down by multilayer adsorption;

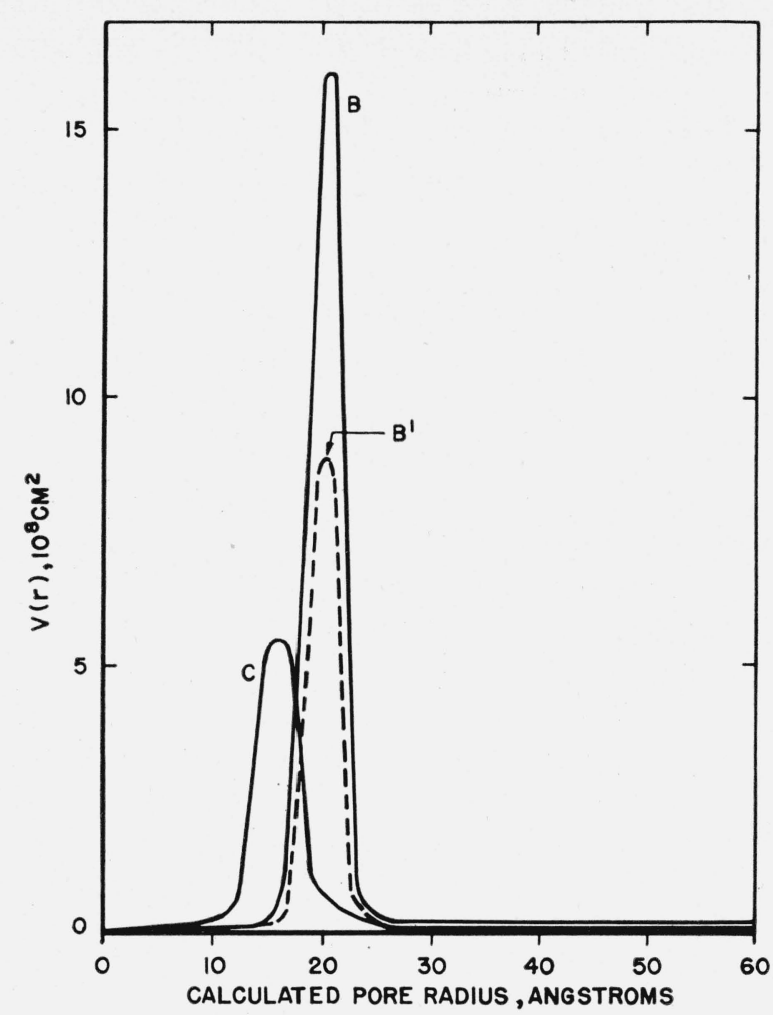

Figure 3. Pore size distribution curves.

B, Alkali swelled, solvent exchanged cotton linters (determination 4); $\mathrm{B}^{\prime}, \mathrm{B}$ conditioned at 20- to 25-percent relative humidity (determination 5); C, water swelled, solvent exchanged cotton linters (determination 2).

$L(r) d r$ is proportional to the total length of pores whose radii fall between $r$ and $r+d r$;

$R$ is the Kelvin radius corrected for multilayer adsorption and is given by the expression:

$$
R=t-\frac{2 \sigma v}{R_{g} T \ln p / p_{0}},
$$

in which:

$\sigma$ is the surface energy of the adsorbate at the temperature of adsorption, $T$;

$v$ is the molar volume of the adsorbate in the liquid state;

$R_{g}$ is the gas constant in ergs/mole/degree;

$p / p_{0}$ is the relative pressure.

Equation 1 is integrated by assuming $L(r)$ is either a Maxwellian distribution,

$$
L(r)=A_{0} r_{0} e^{-r / r_{0}},
$$

or a Gaussian distribution,

$$
L(r)=A_{1} e^{-\frac{B_{1}}{r_{1}}\left(r-r_{1}\right)^{2}}
$$

or the sum of a Maxwellian and a Gaussian distribution, 


$$
L(r)=A_{0} r_{0} e^{-r / r_{0}}+A_{1} e^{-\frac{B_{1}}{r_{1}}\left(r-r_{1}\right)^{2}} .
$$

$A_{0}$ and $A_{1}$ are constants, and $r_{0}, r_{1}$, and $B_{1}$ are parameters.

By way of illustration, when the equation for a Maxwellian distribution [13a] is substituted in eq 1 and the integration carried out, the expression

$$
V_{s}-V=A_{0} r_{0}{ }^{4} M\left(R, r_{0}\right),
$$

is obtained, where $M\left(R, r_{0}\right)$ is a function of $R, r_{0}$, and contains $t$, the multilayer thickness. Shull has calculated this function for a number of values of $R$ and $r_{0}$ and prepared a family of standard inverted isotherms by plotting $M\left(R, r_{0}\right)$ on the logarithmic scale of semilog paper against $R$. Experimental $V_{s}-V$ values are similarly plotted on a logarithmic scale against $R$, and the curve matched with the standard isotherms to find one giving the closest fit. This gives the parameters of the standard distribution most closely approximating the experimental distribution, and the constant $A_{0}$ may be obtained by substituting values of $r_{0}, M\left(R, r_{0}\right)$, and $V_{s}-V$ in eq 4 . The procedure is similar for a Gaussian distribution, and entails a few more steps for the sum of a Maxwellian and a Gaussian distribution, but involves curve matching in each case. The total volume of gas sorbed in pores with radii between $r$ and $r+d r$ is $V(r) d r$, and this volume distribution function is given by

$$
V(r)=\pi r^{2} L(r) .
$$

Certain assumptions have been made in applying this method. First is the basic assumption of the method itself that the sorption process takes place in circular pores whose radii may be calculated from the Kelvin equation, corrected for multilayer adsorption. It has also been assumed that $V s$, the volume of nitrogen required to condense and exactly fill the pores may be obtained by extrapolating the isotherm to saturation pressure, and it has been assumed that the adsorbent undergoes no important dimensional changes during sorption.

Sample $B$ (fig. 3, curve B) is shown as having most of the nitrogen sorbed within a rather narrow distribution of pore radii with a maximum volume at a pore radius of $20 \mathrm{~A}$. When the sample was conditioned at 20 - to 25 -percent relative humidity (fig. 3 , curve $B^{\prime}$ ), the position of the maximum remained about the same. The mechanism by which addition of water to expanded cotton reduced subsequent capacity for nitrogen is not clear at present. It is difficult to visualize a uniform multilayer process by which water could be deposited in pores without decreasing pore radius. If it is assumed that a certain fraction of the entire pore length in the sample was completely destroyed by water while the remainder was left intact, pore volume could be decreased without changing pore radius. The volume of water added was nearly large enough to account for the decreased pore volume if it merely took up space and exerted no specific action in the collapse of the structure. Eleven percent of water was more than enough to account for the pore volume of the original sample on this basis, which suggests additional swelling of the expanded cotton took place upon conditioning at 70 - to 75 -percent relative humidity.

When the desorption measurements on solvent exchanged cotton (fig. 3, curve C) were analyzed by the Wheeler-Shull method, a slightly broader distribution of pore radii with a maximum at $16 \mathrm{~A}$ was obtained.

No curves are shown for the control sample or the cotton conditioned at 70 - to 75 - percent relative humidity. This is because of the difficulty in estimating $V s$ for a type II curve. For a true multilayer adsorption process on a plane surface, $V s$ should approach infinity, and a pore volume calculation would have no physical significance.

\section{Summary}

A sample of cotton linters swollen with strong alkali and given a solvent exchange treatment was found to have a large surface area available to nitrogen. This confirms the observation of Assaf, Haas, and Purves. The shape of the adsorption and desorption isotherms were found to be more like type IV than type II, and they showed strong hysteresis. Pore size distributions, calculated by the method of Wheeler and Shull, showed most of the nitrogen absorbed in pores having radii of about $20 \mathrm{~A}$.

Addition of about 3.3-percent moisture to the expanded cotton reduced the surface area greatly without noticeably changing the type of isotherm or pore radius. Addition of about 11.0-percent moisture destroyed nearly all of the internal 
surface, and the isotherm more closely resembled that of untreated cotton, but a slight hysteresis remained.

Cotton swollen with water only and given solvent exchange also had a much larger surface than untreated cotton. The isotherm was more nearly type IV, and most of the nitrogen was adsorbed in pores having calculated radii of about $16 \mathrm{~A}$.

\section{References}

[1] A. Frey-Wyssling, Protoplasma 27, 372 (1937).

[2] A. Frey-Wyssling, Protoplasma 27, 563 (1937).

[3] O. Kratky and F. Schossberger, Z. Physik. Chem. B39, 145 (1938).

[4] Cellulose and cellulose derivatives, ed. Emil Ott (Interscience Publishers, Inc., New. York, N. Y., 1943) a, Charles W. Hock and H. Mark, pp. 346 to 351 ; b, E. I. Valko, pp. 415 to 419.

[5] G. E. Collins, J. Textile Inst. 21, T311 (1930).

[6] G. E. Collins, J. Textile Inst. 30, P46 (1939).

[7] T. M. Shaw, J. Chem. Phys. 12, 391 (1944).

[8] K. J. Palmer, T. M. Shaw, and M. Ballantyne, J. Polymer Sci. 2, 318 (1947).

[9] A. G. Assaf, R. H. Haas, and C. B. Purves, J. Am. Chem. Soc. 66, 59 (1944).
[10] A. G. Assaf, R. H. Haas, and C. B. Purves, J. Am. Chem. Soc. 66, 66 (1944).

[11] C. G. Shull, J. Am. Chem. Soc. 70, 1405 (1948).

[12] C. G. Shull, P. B. Elkin, and L. C. Roess, J. Am. Chem. Soc. 70, 1410 (1948).

[13] Stephen Brunauer, The adsorption of gases and vapors (Princeton Univ. Press, 1945). a, p. 150; b, p. 155; c, Chapter XI.

[14] P. H. Emmett, A new method for measuring the surface areas of finely divided materials and for determining the size of particles. Symposium on New Methods for Particle Size Determination in the Subsieve Range ASTM 1941, p. 95 to 105.

[15] S. Brunauer, P. H. Emmett, and E. Teller, J. Am. Chem. Soc. 60, 309 (1938).

[16] J. W. Rowen and R. L. Blaine, Ind. Eng. Chem. 39, 1659 (1947).

[17] R. Howell and A. Jackson, J. Chem. Soc. p. 979 to 982 (1937).

[18] S. S. Kistler, J. Phys. Chem. 36, 52 (1932).

[19] Terrel L. Hill, J. Chem. Phys. 15, 767 (1947).

[20] A. Frey-Wyssling, Kolloid Z. 85, 148 (1938).

[21] A. Wheeler, Presentation at Catalysis Symposia, Gibson Island, AAAS Conferences (June 1945 and June 1946).

Washington, July 14, 1949. 